\title{
Effect of interstimulus interval on visual P300 in Parkinson's disease
} Lihong Wang, Yoshiyuki Kuroiwa, Toshiaki Kamitani, Tatsuya Takahashi, Yume Suzuki,
Osamu Hasegawa
Department of Neurology, Yokohama City University School of Medicine, 3-9 Fukuura,

Kanazawa-ku, Yokohama, 236-0004, Japan

L Wang

Y Kuroiwa

T Kamitani

T Takahashi

Y Suzuki

O Hasegawa

Correspondence to: Dr Yoshiyuki Kuroiwa, Department of Neurology, Yokohama City University School of Medicine, 3-9 Fukuura, Kanazawa-ku,

Yokohama, 236-0004, Japan. Telephone 008145787 2800; fax 0081457886041 .

Received 23 November 1998 and in final form

4 May 1999

Accepted 13 May 1999.

\begin{abstract}
Objective-Visual event related potentials (ERPs) were studied during an oddball paradigm, to testify whether cognitive slowing in Parkinson's disease exists and to investigate whether cognitive information processing can be influenced by different interstimulus intervals (ISIs) of an oddball task in patients with Parkinson's disease and normal subjects.

Methods-ERPs and reaction time were measured in 38 non-demented patients with Parkinson's disease and 24 healthy elderly subjects. A visual oddball paradigm was employed to evoke ERPs, at three different interstimulus (ISI) intervals: ISI(S), $1600 \mathrm{~ms}$; ISI(M), $3100 \mathrm{~ms}$; and ISI(L), $5100 \mathrm{~ms}$. The effect of ISIs on ERPs and reaction time was investigated.

Results-Compared with the normal subjects, P300 latency at $\mathrm{Cz}$ and $\mathrm{Pz}$ was significantly delayed after rare target stimuli in patients with Parkinson's disease only at ISI(L). Reaction time was prolonged in patients at all the three ISIs, compared with the normal controls. There was also significantly delayed N200 and reduced $\mathrm{P300}$ amplitude at $\mathrm{Cz}$ and/or $\mathrm{Pz}$ to rare non-target stimuli in patients at the three ISIs, compared with the normal controls. During rare target visual stimulation, P300 latency and reaction time in the patients with Parkinson's disease and reaction time in the normal subjects were gradually prolonged as the ISI increased. Conclusion-Prolonged N200 latency to rare non-target stimuli might indicate that automatic cognitive processing was slowed in Parkinson's disease. Cognitive processing reflected by $\mathrm{P} 300$ latency to rare target stimuli was influenced by longer ISI in patients with Parkinson's disease.

(f Neurol Neurosurg Psychiatry 1999;67:497-503)
\end{abstract}

Keywords: P300; interstimulus interval; oddball paradigm; Parkinson's disease

It has been a long debated question whether or not there exists cognitive slowing in Parkinson's disease. ${ }^{1-5}$ The neuropsychological tests employed to evaluate cognitive slowing are extremely varied. Until now, no consistent conclusion has been reached on the existence and nature of the cognitive slowing in Parkinson's disease. It is sometimes difficult to evaluate mental processing in patients with Parkinson's disease accurately by neuropsychological assessments, as they might be influenced by parkinsonian motor deficits during the task. P300 latency, which is presumed to indicate the time required for task evaluation independent of motor processing, ${ }^{6}$ may be useful in studying the cognitive processing in the disease. There are some reports which provide evidence of cognitive slowing during auditory or visual oddball tasks by showing delayed P300 in Parkinson's disease..$^{7-11}$ However, there are also reports showing normal P300 latency in such patients. ${ }^{12-15}$

P300 is usually evoked by an oddball task with an interstimulus interval (ISI) of $1000 \mathrm{~ms}$ to $2000 \mathrm{~ms}$. The load on cognitive processing systems varies with the rate at which information is presented - that is, with the duration of the ISIs. A too fast or too slow stimulus presentation sometimes may make the task difficult to follow and to perform. Cognitive slowing in Parkinson's disease is presumed to be found only in tasks that place greater demands on the subject's cognitive capacity. ${ }^{16}$ Therefore, we presumed that different rates of information presentation due to different ISIs of an oddball task may change the difficulty of the task, and possibly can induce cognitive slowing in Parkinson's disease. There have been few studies on the influences of different presentation rates on cognitive processing in patients with Parkinson's disease and normal subjects.

In this study, we intended to investigate whether the changes of visual event related potentials occur during rare target and rare non-target stimulation when different ISIs are used. To testify whether cognitive slowing in Parkinson's disease exists, and to study whether cognitive information processing can be influenced by different ISIs in patients with Parkinson's disease and normal subjects, visual ERPs and reaction time were measured during a modified oddball paradigm at short, medium, and long interstimulus intervals: ISI(S), 1600 $\mathrm{ms}$; ISI(M), $3100 \mathrm{~ms}$; and ISI(L), $5100 \mathrm{~ms}$.

\section{Methods}

SUBJECTS

The subjects were 38 patients (14 men, 24 women) with the definite clinical diagnosis of idiopathic Parkinson's disease and 24 elderly healthy volunteers (11 men, 13 women). The age of the Parkinson's disease group ranged from 41 to 77 years, with a mean (SD) of 65.8 (8.8) years. The age of the normal control group ranged from 42 to 79 years, with a mean (SD) of 65.2 (10.3) years. All control subjects showed normal neurological findings and had no specific neurological diseases. None exhib- 
Table 1 Backgrounds of patients with Parkinson's disease

\begin{tabular}{lc}
\hline & 38 \\
Total No of patients & $65.8(8.8)$ \\
Age (y) (mean (SD)) & $7.4(7.8)$ \\
Duration of illness (y) (mean (SD)) & \\
Hoehn and Yahr stage (No of cases) & 4 \\
$\quad$ Stage I & 19 \\
$\quad$ Stage II & 7 \\
$\quad$ Stage III & 8 \\
Stage IV & 0 \\
$\quad$ Stage V & \\
WAIS-R scores (mean (SD)) & $93.8(13.6)$ \\
$\quad$ Full IQ & $98.5(14.6)$ \\
$\quad$ Verbal IQ & $89.9(13.5)$ \\
$\quad$ Performance IQ & $367.2(158.4)$ \\
Levodopa dosage (38 cases) (mg/day) \\
$\quad$ (mean (SD)) \\
Trihexyphenidyl dosage (12 cases) \\
$\quad$ (mg/day) (mean (SD))
\end{tabular}

*The levodopa dosage in the table represents the dosage of levodopa in Neodopaston ${ }^{\circledR}$ which contains levodopa and carbidopa.

ited any abnormal MRI findings. They also had no history of medical or psychiatric disorders. All patients fulfilled Parkinson's Disease Society Brain Bank clinical criteria ${ }^{17}$ for definite disease. Patients with secondary parkinsonism or with evidence of focal cerebral lesions were excluded from the study. Any patients diagnosed as having dementia according to the criteria of the diagnostic and statistical manual of mental disorders, third edition, revised, ${ }^{18}$ were excluded from the study. All patients were treated with antiparkinsonian medication. Table 1 shows the details of the patients with Parkinson's disease. All the subjects gave signed informed consent after the purpose of the study and the protocol had been explained to them, and before any procedures were performed.

ERPS

A modified visual oddball paradigm which was previously designed by Tachibana et $a l^{19}$ was used to elicit ERPs (fig 1). The paradigm employed three kinds of visual stimuli: rare target, rare non-target, and frequent non-target. They were presented on an electronic tachistoscope screen (Iwasaki Tsushin), at event probabilities of $20 \%, 20 \%$, and $60 \%$, respectively. The duration of each stimulus was $68 \mathrm{~ms}$. The ISI was defined as the interval between the appearance of each sequential stimulus. The task was performed at short, medium, and long ISI separately in the order of ISI(S) $1600 \mathrm{~ms}$ (stimulus rate $0.625 \mathrm{~Hz}$ ), ISI(M) $3100 \mathrm{~ms}$ (stimulus rate $0.322 \mathrm{~Hz}$ ), and ISI(L) $5100 \mathrm{~ms}$ (stimulus rate $0.196 \mathrm{~Hz}$ ). The subjects were instructed to press the button for rare target stimuli as rapidly and correctly as possible. Data were recorded only after the subjects understood the tasks completely through a training period.

ERPs were recorded with $\mathrm{Ag} / \mathrm{AgCl}$ electrodes from $\mathrm{Cz}$ and $\mathrm{Pz}$ referred to linked earlobes. The EOG was monitored using a forehead-temple montage with a rejection level of $\pm 100 \mu \mathrm{V}$. Electrode impedance was maintained below $5 \mathrm{~K} \Omega$. Bandwidth of preamplifiers ranged from 0.1 to $50 \mathrm{~Hz}$. Each block included four rare target stimuli. Three or four blocks with breaks of 2 minutes between blocks comprised one section. Therefore, each section contained 12 to 16 responses to rare target stimuli. Each section was repeated once to confirm the reliability of recording for each ISI. The EEG activity was analysed $100 \mathrm{~ms}$ before and $900 \mathrm{~ms}$ after each visual presentation. On the traces, upward deflection of the ERP waveform indicated positive activity.

N200 was identified as a negative component (peak or notch) at $\mathrm{Cz}$ and $\mathrm{Pz}$ occurring 200-400 ms after the start of the stimulus. P300 was identified as a positive wave at $\mathrm{Cz}$ and $\mathrm{Pz}$, with latency of $300-700 \mathrm{~ms}$ after the start of the stimulus. N200 latency and P300 latency were measured as the interval between each peak (or notch) and the onset of the stimulus. P300 amplitude was defined as the voltage difference between the P300 peak and the prestimulus baseline (averaging voltage of $100 \mathrm{~ms}$ before the stimulus). Reaction time was defined as the interval between the start of rare target and the button press.

\section{STATISTICAL ANALYSIS}

A two tailed Student's $t$ test was used to compare the ERPs (N200 latency, P300 latency, and P300 amplitude) or reaction time between the Parkinson's disease and normal groups at each of the three ISIs. One way repeated measures ANOVA was computed to study the effect of ISIs on ERPs (N200 latency, P300 latency, and P300 amplitude) or reaction time in the Parkinson's disease group and the normal control group, separately. Two way repeated measures ANOVA was also studied using the groups (Parkinson's disease $v$ normal controls) as the between subjects factor and different ISIs as the within subjects factor. When ANOVA yielded significant differences among data sets, a Bonferroni/Dunn test was performed as a post hoc test.

\section{Results}

All the normal subjects accurately performed the task. All patients with Parkinson's disease performed the task at an error rate not exceeding $5 \%$ after the training period.

According to the averaged waveforms in Parkinson's disease (fig 2), P300 latency seems to be longer after rare target stimuli at ISI(L) than at ISI(S) and ISI(M). P300 amplitude after rare non-target stimuli in patients with Parkinson's disease was markedly reduced compared with that in normal controls at all the three ISIs.

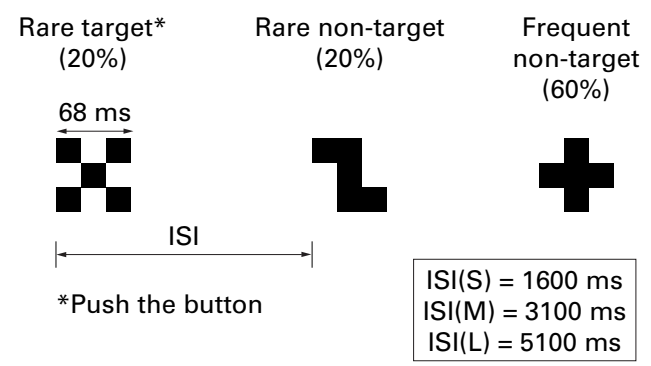

Figure 1 Sketch representing the time course of the modified oddball paradigm at three different ISIs. 


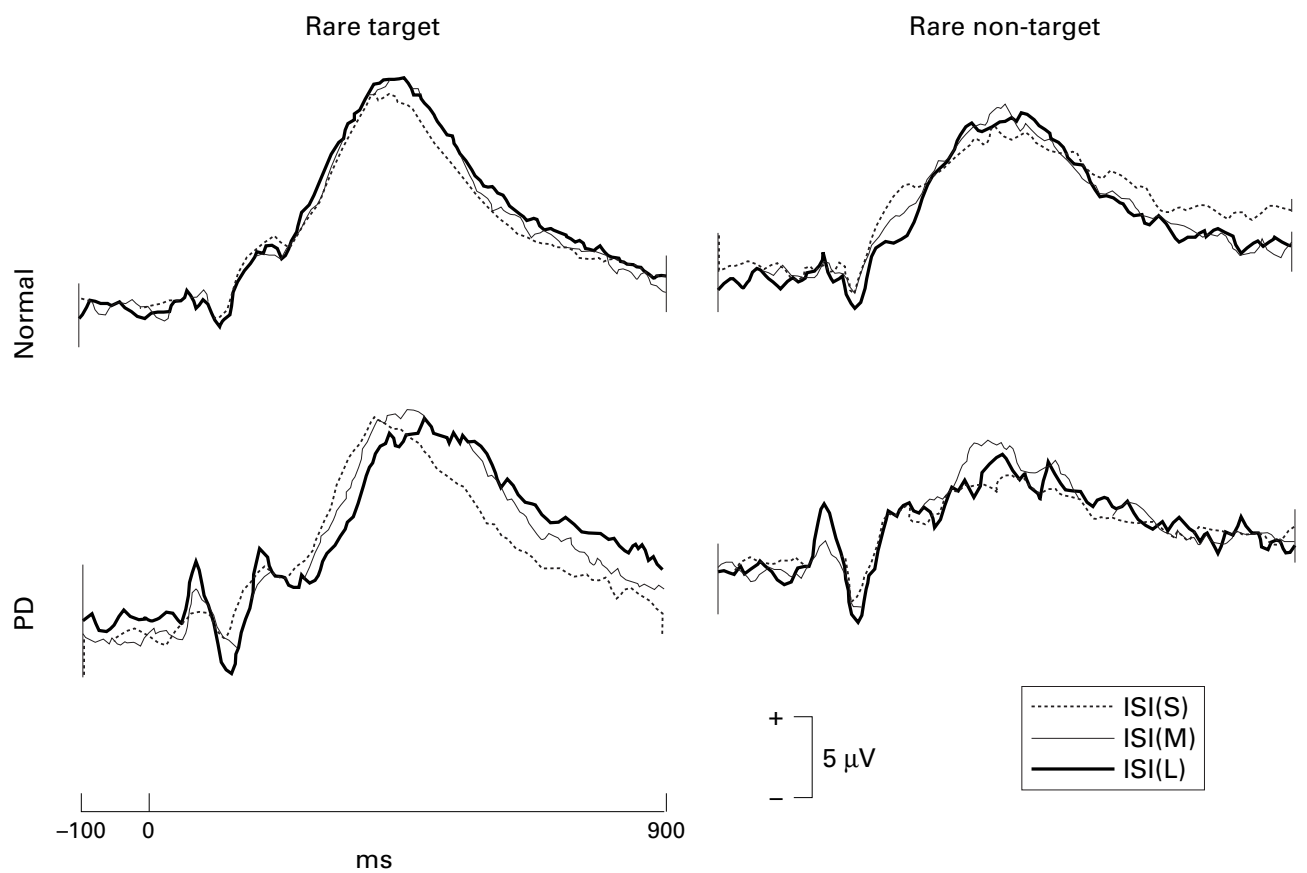

Figure 2 Averaged waveforms of ERPs at Pz after rare target and rare non-target at $I S I(S), \operatorname{ISI}(M)$, and $I S I(L)$ of the Parkinson's disease (PD) and the normal control groups.

COMPARISON OF ERPS AND REACTION TIME BETWEEN PATIENTS WITH PARKINSON'S DISEASE AND NORMAL CONTROL GROUPS

We compared the data between patients with Parkinson's disease and normal control groups using Student's $t$ test (tables 2 and 3). Prolonged P300 latency at $\mathrm{Cz}$ and $\mathrm{Pz}$ after rare target stimuli in Parkinson's disease was found only at ISI(L) $(\mathrm{Cz}, t=2.408, \mathrm{df}=52, \mathrm{p}<0.05 ; \mathrm{Pz}$, $t=2.232, \mathrm{df}=52, \mathrm{p}<0.05)$. No significant $\mathrm{N} 200$ latency or P300 amplitude difference to rare target stimuli was found between groups at any of the three ISIs. Significantly delayed N200 at $\mathrm{Cz}$ or $\mathrm{Pz}$ to rare non-target stimuli in Parkinson's disease was found at the three ISIs: ISI(S), $(\mathrm{Pz}, t=2.915, \mathrm{df}=49, \mathrm{p}<0.01)$; ISI $(\mathrm{M})$, $(\mathrm{Cz}, t=2.269, \mathrm{df}=50, \mathrm{p}<0.05)$, and ISI $(\mathrm{L}),(\mathrm{Pz}$, $t=2.871, \mathrm{df}=45, \mathrm{p}<0.01)$. Significantly reduced P300 amplitude at $\mathrm{Cz}$ and $\mathrm{Pz}$ after rare non-target stimuli was found in the Parkinson's disease group compared with the control group at all the ISIs (ISI(S), Cz, $t=2.741, \mathrm{df}=58$, $\mathrm{p}<0.05 ; \mathrm{Pz}, \quad t=2.029, \quad \mathrm{df}=55, \quad \mathrm{p}<0.05$; ISI(M),Cz, $t=2.423, \quad \mathrm{df}=57, \mathrm{p}<0.05 ; \quad \mathrm{Pz}$, $t=2.530, \mathrm{df}=56, \mathrm{p}<0.05 ; \mathrm{ISI}(\mathrm{L}), \mathrm{Cz}, t=2.508$, $\mathrm{df}=51, \mathrm{p}<0.05 ; \mathrm{Pz}, t=2.408, \mathrm{df}=51, \mathrm{p}<0.05)$. Reaction time to rare target stimuli in Parkinson's disease was significantly delayed compared with that in the control group at all the ISIs (ISI(S), $t=2.098, \mathrm{df}=51, \mathrm{p}<0.05$; ISI(M), $t=2.475, \mathrm{df}=49, \mathrm{p}<0.05 ; \mathrm{ISI}(\mathrm{L}), t=2.483$, $\mathrm{df}=48, \mathrm{p}<0.05)$.

EFFECT OF ISI ON ERPS AND REACTION TIME IN PATIENTS WITH PARKINSON'S DISEASE AND NORMAL CONTROLS

We applied one way repeated measures ANOVA to study the effect of the three ISIs on N200 and P300 components and reaction time in the Parkinson's disease and the normal group, separately. In the normal control group, no ISI effect was found on any of ERP components after rare target and rare non-target stimuli. In the Parkinson's disease group, only P300 latency after rare target stimuli was found to be significantly influenced by different ISIs

Table 2 Comparison of the mean (SD) values of ERPs at $P z$ and reaction time $(R T)$ to rare target stimuli between patients with Parkinson's disease (PD) and normal controls at the three ISI conditions

\begin{tabular}{|c|c|c|}
\hline & PD patients & Normal controls \\
\hline \multicolumn{3}{|c|}{ N200 latency (ms): } \\
\hline ISI(S) & $265.4(35.1)$ & $261.4(32.8)$ \\
\hline ISI $(M)$ & $266.5(44.6)$ & $247.2(45.5)$ \\
\hline ISI(L) & $267.3(43.9)$ & $248.3(30.6)$ \\
\hline \multicolumn{3}{|c|}{ P300 latency (ms): } \\
\hline ISI(S) & $434.5(55.2)$ & $424.2(42.7)$ \\
\hline ISI $(M)$ & $452.2(61.0)$ & 439.7 (41.4) \\
\hline ISI(L) & $466.3(63.5)^{\star}$ & $432.6(40.0)$ \\
\hline \multicolumn{3}{|c|}{ P300 amplitude $(\mu \mathrm{V})$ : } \\
\hline ISI(S) & $15.8(8.0)$ & $18.7(4.5)$ \\
\hline ISI $(M)$ & $15.7(8.6)$ & $19.0(7.5)$ \\
\hline ISI(L) & $17.5(9.3)$ & $19.9(6.5)$ \\
\hline \multicolumn{3}{|l|}{ RT (ms): } \\
\hline ISI(S) & $515.6(161.4)^{\star}$ & $437.2(68.6)$ \\
\hline ISI(M) & $654.5(348.2)^{\star}$ & $462.4(81.6)$ \\
\hline ISI(L) & $679.1(339.1)^{\star}$ & $488.9(103.1)$ \\
\hline
\end{tabular}

${ }^{\star} \mathrm{p}<0.05$; Student's $t$ test.

Table 3 Comparison of the mean (SD) values of ERPs at $P z$ to rare non-target stimuli between patients with

Parkinson's disease (PD) and normal controls at the three ISI conditions

\begin{tabular}{lcc}
\hline & \multicolumn{1}{c}{ PD patients } & Normal controls \\
\hline \multicolumn{2}{c}{ N200 latency $(\mathrm{ms}):$} & \\
ISI(S) & $275.4(41.0)^{\star \star}$ & $243.6(35.1)$ \\
ISI(M) & $257.4(33.7)$ & $241.2(30.8)$ \\
ISI(L) & $263.7(34.7)^{\star \star}$ & $235.9(31.2)$ \\
P300 latency $(\mathrm{ms}):$ & & \\
ISI(S) & $437.8(72.0)$ & $411.5(48.2)$ \\
ISI(M) & $418.5(62.8)$ & $419.5(46.0)$ \\
ISI(L) & $434.3(65.4)$ & $419.2(48.5)$ \\
PI00 amplitude $(\mu \mathrm{V}):$ & \\
ISI(S) & $8.7(6.0)^{\star}$ & $11.8(4.8)$ \\
ISI(M) & $10.3(5.7)^{\star}$ & $14.0(5.3)$ \\
ISI(L) & $9.3(6.4)^{\star}$ & $13.2(5.0)$
\end{tabular}

${ }^{\star} \mathrm{p}<0.05 ;{ }^{\star \star} \mathrm{p}<0.01$; Student's $t$ test. 

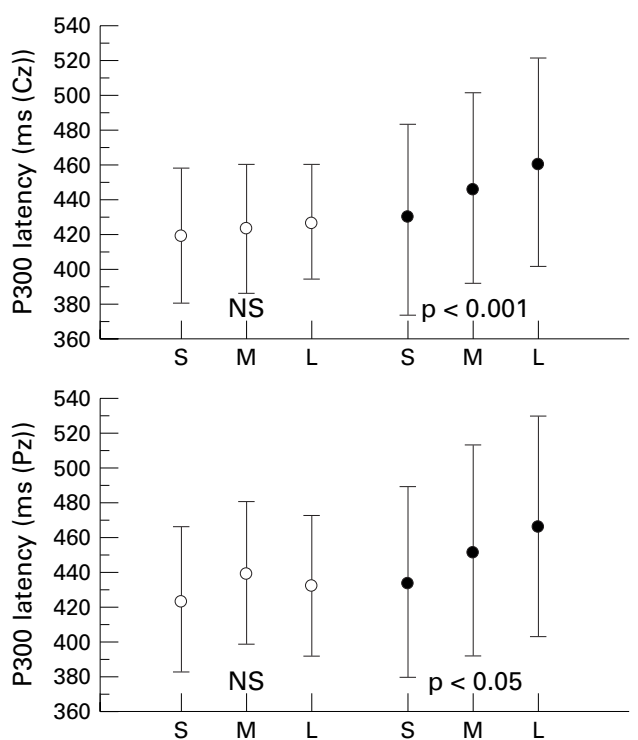

Figure 3 ISI effect on P300 latency at $\mathrm{Cz}$ and $\mathrm{Pz}$ in normal control group (open circles) and Parkinson's disease group (closed circles). S, M, and L indicate ISI(S), $I S I(M)$ and ISI $(L)$, respectively. The $p$ value represents the effect of ISIs on P300 latency by one way repeated measures ANOVA. NS=no significant difference among three ISIs by one way repeated measures ANOVA.

(one way repeated measures ANOVA, Cz, $F=8.094, \mathrm{p}<0.001 ; \mathrm{Pz}, F=5.006, \mathrm{p}<0.05 ;$ fig 3 and table 4). P300 latency at ISI(L) was significantly longer than at ISI(S) (Bonferroni/ Dunn post hoc, $\mathrm{Cz}, \mathrm{p}<0.05 ; \mathrm{Pz}, \mathrm{p}<0.05)$. No ISI effect was found on any other ERP components after rare target and rare non-target stimuli in the Parkinson's disease group.

A significant ISI effect on reaction time was found in both the Parkinson's disease group (one way repeated measures ANOVA, $F=8.769$, p<0.001; fig 4 and table 4 ) and the normal control group (one way repeated measures ANOVA, $F=6.122, \mathrm{p}<0.01)$. Reaction time at ISI(L) was significantly longer than reaction time at ISI(S) (Bonferroni/Dunn post hoc, $\mathrm{p}<0.05)$ in the Parkinson's disease group and tended to be longer than reaction time at ISI(S) in the normal control group (Bonferroni/Dunn post hoc, $\mathrm{p}=0.0554$ ).

THE EFFECTS OF GROUPS AND ISIS ON ERPS AND REACTION TIME

Two way repeated measures ANOVA using the different groups (Parkinson's disease $v$ normal controls) as the between groups factor and the different ISIs as the within subjects factor confirmed that different ISIs produced a significant P300 latency difference during rare target

Table 4 Significant effect of ISI on ERP and reaction time (RT) to rare target stimuli in patients with Parkinson's disease (PD) and normal controls during one way repeated measures ANOVA

\begin{tabular}{lll}
\hline & Normal controls & PD patients \\
\hline P300 latency $(\mathrm{Cz})$ & $F=0.578$, & $\mathrm{F}=8.094$, \\
& $\mathrm{p}=0.5654$ & $\mathrm{p}=0.0008^{\star \star \star}$ \\
P300 latency $(\mathrm{Pz})$ & $F=1.798$, & $\mathrm{F}=5.006$, \\
& $\mathrm{p}=0.1775$ & $\mathrm{p}=0.0101^{\star}$ \\
RT to rare target & $\mathrm{F}=6.122$, & $\mathrm{F}=8.769$, \\
& $\mathrm{p}=0.0048^{\star \star}$ & $\mathrm{p}=0.0005^{\star \star \star}$ \\
\hline
\end{tabular}

${ }^{\star} \mathrm{p}<0.05,{ }^{\star \star} \mathrm{p}<0.01 ;{ }^{\star \star \star} \mathrm{p}<0.001$.

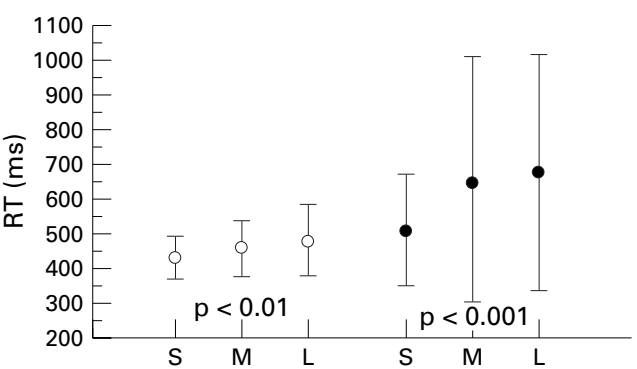

Figure 4 ISI effect on reaction time in normal control group (open circles) and Parkinson's disease group (closed circles). S, M, and L indicate ISI(S), ISI(M), and ISI(L), respectively. The $p$ value represents the effect of ISIs on reaction time by one way repeated measures ANOVA. $N S=$ no significant difference among three ISIs by one way repeated measures ANOVA.

stimuli (Cz, F=5.413, p<0.01; Pz, F=6.209, $\mathrm{p}<0.01)$. P300 latency at ISI(L) was significantly longer than at ISI(S) (Bonferroni/Dunn post hoc, $\mathrm{Cz}, \mathrm{p}<0.05$; $\mathrm{Pz}, \mathrm{p}<0.05)$. However, different groups or the interaction of groups $\times$ ISIs did not influence P300 latency to rare target stimuli significantly. Different groups made significant differences on N200 latency $(\mathrm{Cz}, F=7.415, \mathrm{p}<0.01 ; \mathrm{Pz}, F=9.595$, $\mathrm{p}<0.01)$ and $\mathrm{P} 300$ amplitude $(\mathrm{Cz}, F=8.905$, $\mathrm{p}<0.01 ; \mathrm{Pz}, F=8.220, \mathrm{p}<0.01)$ to rare nontarget stimuli. The patient group showed significantly prolonged $\mathrm{N} 200$ latency (Bonferroni/Dunn post hoc, Cz, p<0.01; Pz, $\mathrm{p}<0.0001$ ) and reduced $\mathrm{P} 300$ amplitude (Bonferroni/Dunn post hoc, $\mathrm{Cz}, \mathrm{p}<0.0001 ; \mathrm{Pz}$, $\mathrm{p}<0.0001)$ to rare non-target stimuli compared with the control group. However, different ISIs or the interaction of groups $\times$ ISIs made no significant difference on N200 latency and P300 amplitude to rare non-target stimuli. Different groups, different ISIs, and the interaction of groups $\times$ ISIs influenced reaction time to rare target stimuli significantly (different groups, $F=6.441, \mathrm{p}<0.05$; different ISIs, $F=12.069$, p<0.0001; groups $\times$ ISIs, $F=3.339, \mathrm{p}<0.05)$. The patient group showed significantly more prolonged reaction time than the control group (Bonferroni/Dunn post hoc, $\mathrm{p}<0.001$ ). Reaction time at ISI(L) was significantly more prolonged than reaction time at ISI(S) (Bonferroni/Dunn post hoc, $\mathrm{p}<0.05$ ). Neither different groups nor different ISIs had a significant effect on N200 latency and P300 amplitude to rare target stimuli, or P300 latency to rare non-target stimuli. Table 5 is a summary of the main significant findings in two way repeated measures ANOVA.

MEASUREMENT OF P300 LATENCY DIFFERENCE (RATIO) AND REACTION TIME DIFFERENCE (RATIO) IN PATIENTS WITH PARKINSON'S DISEASE AND NORMAL CONTROL GROUPS

As P300 latency and reaction time to rare target stimuli were found to be influenced by different ISIs, we measured P300 latency difference (or ratio) and reaction time difference (or ratio) for two different ISIs. P300 latency differences to rare target stimuli were defined as (P300 latency at ISI(M)-P300 latency at ISI(S)); (P300 latency at ISI(L)-P300 latency at ISI(M)); and (P300 latency at ISI(L)-P300 latency at $\operatorname{ISI}(\mathrm{S}))$. reaction time differences 
Table 5 Significant group and/or ISI effect on ERPs and RT found during two way repeated measures $A N O V A$

\begin{tabular}{llll}
\hline & \multicolumn{2}{l}{ Two way repeated measures ANOVA } \\
\cline { 2 - 4 } & Group effect & ISI effect & $\begin{array}{l}\text { Group } \times \text { ISI } \\
\text { effect }\end{array}$ \\
\hline P300 latency to rare target $(\mathrm{Pz})$ & $F=1.873$ & $F=6.209$ & $F=1.766$ \\
N200 latency to rare non-target (Pz) & $\mathrm{p}=0.177$ & $\mathrm{p}=0.003^{\star \star}$ & $\mathrm{p}=0.177$ \\
& $F=9.595$ & $F=2.737$ & $F=0.524$ \\
P300 amplitude to rare non-target $(\mathrm{Pz})$ & $\mathrm{p}=0.004^{\star \star}$ & $\mathrm{p}=0.07$ & $\mathrm{p}=0.59$ \\
& $\mathrm{p}=0.220$ & $F=2.770$ & $F=0.950$ \\
RT to rare target & $F=6.441$ & $\mathrm{p}=0.07$ & $\mathrm{p}=0.91$ \\
& $\mathrm{p}=0.015^{\star}$ & $\mathrm{p}=<0.000$ & $F=3.339$ \\
& & & $\mathrm{p}=0.04 \star$ \\
\hline
\end{tabular}

${ }^{\star} \mathrm{p}<0.05 ;{ }^{\star \star} \mathrm{p}<0.01 ;{ }^{\star \star \star} \mathrm{p}<0.001 ;{ }^{\star \star \star \star} \mathrm{p}<0.0001$.

were defined as (reaction time at ISI $(M)$-reaction time at ISI(S)); (reaction time at ISI(L)-reaction time at ISI $(\mathrm{M}))$; and (reaction time at $\mathrm{ISI}(\mathrm{L})$ - reaction time at ISI(S)). P300 latency ratios to rare target stimuli were defined as (P300 latency at ISI(M)/P300 latency at ISI(S)); (P300 latency at ISI(L)/P300 latency at ISI(M)); and (P300 latency at ISI(L)/P300 latency at ISI(S)). Reaction time ratios were defined as (reaction time at ISI(M)/reaction time at ISI(S)); (reaction time at ISI(L)/reaction time at ISI(M)); and (reaction time at $\mathrm{ISI}(\mathrm{L}) /$ reaction time at ISI(S)). We compared the above parameters between groups by Student's $t$ test. Only P300 latency difference of (P300 latency at ISI(L)-P300 latency at ISI(M)) at $\mathrm{Cz}$ and P300 latency ratio of (P300 latency at ISI(L)/ P300 latency at ISI(M)) at Cz were significantly greater in patients with Parkinson's disease than those in normal controls (latency difference, $t=-2.098, \mathrm{p}<0.05$; latency ratio, $t=-2.050, \mathrm{p}<0.05)$.

\section{Discussion}

We found significantly delayed N200 and reduced $\mathrm{P} 300$ amplitude at $\mathrm{Cz}$ and/or $\mathrm{Pz}$ to rare non-target stimuli at all the three ISIs, and prolonged P300 latency at $\mathrm{Cz}$ and $\mathrm{Pz}$ to rare targets only at ISI(L). Visual N200 to rare target stimuli was thought to be similar to auditory $\mathrm{N} 2 \mathrm{~b}^{20}$ and to be reflected an controlled discrimination processing. ${ }^{21}$ However, our visual N200 to rare non-target stimuli was more similar to N2b described by Squires et al, which appeared while the subject was paying unconscious attention and should reflect an automatic task evaluation processing. ${ }^{22}$ P300 after rare non-target stimuli in our paradigm was also thought to reflect an automatic task evaluation processing, ${ }^{23}$ whereas P300 after rare target stimuli could reflect controlled cognitive processing. ${ }^{23}{ }^{24}$ With regard to the question whether cognitive slowing exists in Parkinson's disease or not, our finding of prolonged N200 latency to rare non-targets implies that the automatic cognitive processing could be slowed in the disease. Dysfunction of automatic processing in Parkinson's disease has also been reported by a recent ERP study. ${ }^{24}$ However, there are neuropsychological studies $^{25}$ which suggested preserved function of automatic cognitive processing in parkinsonian patients. Task differences while evaluating the automatic cognitive processing may be a reason for such a discrepancy. It remains to be elucidated why mean N200 latency in the Parkinson's disease group was delayed to rare non-targets and was not delayed to rare targets. Literature on visual search (popout) shows that, even in normal subjects, verification of the presence of a target is completed more quickly than the decision that a target is absent. ${ }^{26}{ }^{27}$ There is also a study showing that it was significantly worse at discerning the orientation of non-target regions than at detecting target presence. ${ }^{28}$ These results might be related to a self terminating processing theory that a visual search can terminate on the half way when a predesignated target is found, while for a nontarget stimulus (a negative response), visual search must proceed until all features of the stimulus are evaluated. ${ }^{29}$ The significantly delayed N200 to rare non-targets in our study might be a physiological correlate to the self terminating processing, albeit exaggerated in Parkinson's disease.

The controlled processing reflected by $\mathrm{P} 300$ latency after rare targets was slowed only at longer ISI in Parkinson's disease, but not at ISI(S) and ISI(M). Two way ANOVA showed that there was no group difference on P300 latency while taking all the three ISIs as a whole. This result is different from the results of other authors who proved the cognitive slowing during oddball task in Parkinson's disease by showing delayed P300 latency, ${ }^{9-11}$ but in agreement with those who did not find prolonged P300 latency in the disease. ${ }^{12-15}$ Different clinical status such as age at test, age at onset, duration of illness, and treatment may be able to explain such discrepancy on P300 latency. $^{3031}$

Although the interaction of groups $\times$ ISIs did not influence P300 latency to rare target stimuli significantly after two way repeated ANOVA, one way repeated ANOVA showed that P300 latency to rare targets was significantly influenced by different ISIs in the Parkinson's disease group and not in the normal control group. Furthermore, Student's $t$ test on P300 to rare targets showed that (P300 latency at ISI(L)), (P300 latency at ISI(L)-P300 latency at ISI(M)), and (P300 latency at $\operatorname{ISI}(\mathrm{L}) / \mathrm{P} 300$ latency at $\operatorname{ISI}(\mathrm{M}))$ in the Parkinson's disease group showed significantly larger mean values than those in the normal control group. All these results suggested that the ISI effect on P300 to rare targets was rather stronger in the Parkinson's disease group compared with the normal control group. Polich et $a l^{32}$ described significantly longer auditory P300 latency at the ISI of 6 seconds than the P300 latency at the ISI of 2 seconds in normal younger subjects. Literature about ISI effects on P300 latency using visual stimulation in Parkinson's disease is completely lacking. To our knowledge, this is the first report that showed $\mathrm{P} 300$ changes at different ISIs in Parkinson's disease.

One possible explanation for delayed P300 at ISI(L) is that it might be due to the decreasing sustained attention at longer ISI in Parkinson's disease. It is said that sustained attention is impaired in Parkinson's disease. ${ }^{33}{ }^{34}$ In the 
longer ISI condition, the subjects had to try to maintain their attention for a relatively longer period of time. Therefore, too slow information input at ISI(L) might cause an effort demanding task to patients with Parkinson's disease. Further, to get the same number of trials per ISI condition, the total test session would be much longer in the longer ISI condition. Also, the ISI(L) task was always performed later than ISI(S) and ISI(M). All these facts could result in low attention at longer ISI. However, if it were a problem of low attention at longer ISI, P300 amplitude reduction instead of prolonged P300 latency, should be more pronounced as P300 amplitude was thought to be directly related to allocating attention capacity. ${ }^{35}$ In our study, P300 amplitude in Parkinson's disease was not influenced by different ISIs.

The problem of short term memory decay might also be a possible explanation for prolonged P300 at ISI(L). The short term memory decay at ISI(L) might be more pronounced than at ISI(S) and ISI(M) and result in a failure of retaining iconic memory on the previous stimulus in Parkinson's disease. However, we do not think that short term memory is crucial enough to produce a P300 difference among varying ISIs in our oddball paradigm. ${ }^{36}$

As another possible explanation for our results, we assumed that the visual stimulus input at ISI(S) was presented at a relatively fast stimulus rate $(0.625 \mathrm{~Hz})$ and could give rise to some sort of rhythmic visual sensation. On the other hand, the visual stimulus rate at ISI(L) was rather slow $(0.196 \mathrm{~Hz})$ and the rhythmic sensation would be relatively weaker. Clinical findings and research showed that patients with Parkinson's disease can gain an improvement in gait disturbance by rhythmic auditory external cues ${ }^{37-42}$ In other words, typical gait disturbance in Parkinson's disease can be seen without rhythmic auditory stimuli. It has remained unknown whether or not mental processing in Parkinson's disease might be facilitated by a visual or auditory rhythmic information input. Although the interpretation of our results might be speculative, lack of such rhythmic visual sensation at ISI(L) could give rise to prolonged P300 latency in the Parkinson's disease group. Comparing P300 during an oddball task at random ISIs with P300 response at a fixed ISI might elucidate this.

Although the normal controls showed longer reaction time at longer ISI, our one way and two way ANOVA results showed that the ISI effect was more prominent in Parkinson's disease. Reaction time is the time from task presentation to button press. It is related to both cognitive and motor processing. We cannot conclude that cognitive processing in Parkinson's disease is impaired at longer ISI with the reaction time result alone. However, with the results of reaction time and P300 latency together, we may speculate that cognitive processing was influenced by different speeds of information input.

In summary, our study on visual event related potentials indicates that there may exist some slowness of automatic cognitive processing in Parkinson's disease, whereas controlled cognitive processing was slowed only at the ISI(L) condition. The ISI effect on P300 latency and reaction time implied that the controlled cognitive processing in Parkinson's disease was influenced by slower information input at longer ISI.

We are grateful to Masaaki Sibuya, Professor of Statistics, Keio University, Tokyo for helpful assistance and comments concerning statistical analysis. We also sincerely thank Ivan Bodis-
Wollner, Professor of Neurology and Ophthalmology, State University of New York, for valuable comments on the paper.

1 Rogers D. Bradyphrenia in parkinsonism: a historical review. Psychol Med 1986;16:257-65.

2 Lee AJ. The concept of bradyphrenia. Rev Neurol 1994;150: 823-6.

3 Pate DS, Margolin DI. Cognitive slowing in Parkinson's disease and Alzheimer's patients: distinguishing bradyphredisease and Alzheimer's patients: distinguishing
nia from dementia. Neurology 1994;44:669-74.

4 Russ MO, Seger L. The effect of task complexity on reaction imes in memory scanning and visual discrimination Parkinson's disease. Neuropsychologia 1995;33:561-75.

5 Spicer KB, Brown GG, Gorell JM. Lexical decision in Parkinson disease: lack of evidence for generalized bradyphrenia. F Clin Exp Neuropsychol 1994;16:457-71

6 McCarthy G, Donchin E. A metric for thought: a comparison of P300 latency and reaction time. Science 1981;211: 77-80.

7 Kutukcu Y, Marks WJ, Goodin DS, et al. Cerebral accompaniments to simple and choice reaction tasks in Parkinson's disease. Brain Res 1998;799:1-5.

8 Tachibana H, Aragane K, Miyata Y, et al. Electrophysiological analysis of cognitive slowing in Parkinson's disease. $f$ Neurol Sci 1997;149:47-56.

9 Hansch EC, Syndulko K, Cohen SN, et al. Cognition in Parkinson disease: an event-related potential perspective. Ann Neurol 1982;11:599-607.

10 Prasher D, Findley L. Dopaminergic induced changes in cognitive and motor processing in Parkinson's disease: an electrophysiological investigation. $\mathcal{F}$ Neurol Neurosurg Psychiatry 1991;54:603-9.

11 Elwan OH, Baradah OH, Madkour O, et al. Parkinson's disease, cognition and aging. Clinical, neuropsychological, electrophysiological and cranial computerized topographic assessment. $\mathcal{F}$ Neurol Sci 1996;143:64-71.

12 Goodin DS, Aminoff MJ. Electrophysiological differences between demented and non-demented patients with Parkinson's disease. Ann Neurol 1987;21:90-4.

13 Stanzione P, Fattapposta F, Giunti P, et al. P300 variations in parkinsonian patients before and during dopaminergic monotherapy: a suggested dopamine component in P300. Electroencephalogr Clin Neurophysiol 1991;80:446-53.

14 Rumbach L, Tranchant C, Viel JF, et al. Event-related potentials in Parkinson's disease: a 12-month follow-up study. F Neurol Sci 1993;116:148-51.

15 Green J, Woodard JL, Sirockman BE, et al. Event-related potential P3 change in mild Parkinson's disease. Mov Dispotential P3 change
ord 1996;11:32-42.

16 Brown RG, Marsden CD. Cognitive function in Parkinson's disease: from description to theory. Trends Neurosci 1990;13:21-9.

17 Hughes AJ, Daniel SE, Kilford L, et al. Accuracy of clinical diagnosis of idiopathic Parkinson's disease: a clinicopathological study of 100 cases. F Neurol Neurosurg Psychiatry 1992;55:181-4.

18 American Psychiatric Association. Diagnostic and statistical manual of mental disorders. 3rd ed, revised (DSM III-R). Washington DC: American Psychiatric Association, 1987.

19 Tachibana H, Toda K, Sugita M. Age-related changes in attended and unattended P3 latency in normal subjects. Int f Neurol Sci 1992;66:277-84.

20 Gaillard AWK, Verduin CJ. Comparisons across paradigms: an ERP study. In: Posner MI, Marin OSM, eds. Attention and performance XI. Lawrence Erlbaum Associates, New and performance XI. Lawrence

21 Novak G, Ritter W, Vaughan HG Jr. The chronometry of attention modulated processing and automatic mismatch attention modulated processing and automatic

22 Squires NK, Squires KC, Hillyard SA. Two varieties of long-latency positive waves evoked by unpredictable auditory stimuli in man. Electroencephalogr Clin Neurophysiol 1975;38:387-401.

23 Tachibana H, Toda K, Sugita M. Actively and passively evoked P3 latency of event-related potentials in Parkinson's disease. F Neurol Sci 1992;111:134-42.

24 Lagopoulos J, Gordon E, Barhamali H, et al. Dysfunctions of automatic (P300a) and controlled (P300b) processing in Parkinson's disease. Neurol Res 1998;20:5-10.

25 Weingartner $\mathrm{H}$, Burns $\mathrm{S}$, Diebel $\mathrm{R}$, et al. Cognitive impairments in Parkinson's disease: distinguishing between impairments in Parkinson's disease: distinguishing between chiatr Res 1984;11:223-35.

26 Enns JT, Rensink RA. Influence of scene-based properties on visual search. Science 1990;247:721-3.

27 Jolicoeur P. Orentation congruency effects in visual search. Can F Psychol 1992;46:280-305. 
28 Scialfa CT, Joffe KM. Preferential processing of target features in texture segmentation. Perception and Psychophysfeatures in texture se

29 Zandt TV, Townsend JT. Self-terminating versus exhaustive processes in rapid visual and memory search: an evaluative review. Perception and Psychophysics 1993;53:563-80.

30 Stanzione P, Semprini R, Pierantozzi M, et al. Age and stage dependency of P300 latency alterations in non-demented Parkinson's disease patients without therapy. Electroencephalogr Clin Neurophysiol 1998;108:80-91.

31 Ebmeimer KP. A quantitative method for the assessment of overall effect from a number of similar electrophysiological studies: description and application to event-related potentials in Parkinson's disease. Electroencephalogr Clin Neurophysiol 1992;84:440-6.

32 Polish J, Bondurant T. P300 sequence effects probability and interstimulus interval. Physiol Behav 1997;61:843-9.

33 Steinman SB, Steinman BA. Vision and attention. I Current models of visual attention. Optom Vis Sci 1998,75: 146-55.

34 Trepanier LL, Saint-Cyr JA, Lozano AM, et al. Neuropsychological consequences of posteroventral pallidotomy for the treatment of Parkinson's disease. Neurology 1998;51:207-15.
35 Kok A. Event-related-potential (ERP) reflections of mental resources: a review and synthesis. Biological Psychology 1997;45:19-56.

36 Barrett G, Starr A. Event-related potentials in disordered short-term memory in man. Electroencephalogr Clin Neurophysiol 1987;(suppl 40):657-63.

37 MaCarthy JA. Unusual phenomenon in Parkinson disease. Ann Neurol 1979;5:499.

38 Enzensberger W, Fischer P-A. Metronome in Parkinson's disease. Lancet 1996;347:1337.

39 McIntosh GC, Brown SH, Rice RR, et al. Rhythmic auditory-motor facilitation of gait patterns in patients with Parkinson's disease. F Neurol Neurosurg Psychiatry 1997;62: $22-6$

40 Morris M, Iansek R, Matyas T, et al. Abnormalities in the stride length-cadence relation in parkinsonian gait. Mov Disord 1998;13:61-9.

41 Nieuwboer A, Feys P, Weerdt W, et al. Is using a cue the clue to the treatment of freezing in Parkinson's disease? Physiotherapy Research International 1997;2:125-34.

42 Thaut MH, McIntosh GC, Rice RR, et al. Rhythmic auditory stimulation in gait training for Parkinson's disease patients. Mov Disord 1996;11:193-200. 